\title{
PRAKTIK LOBI DAN NEGOSIASI OLEH LEGISLATOR SEBAGAI BENTUK KOMUNIKASI POLITIK
}

\author{
Ardianto1, Guntur F. Prisanto1', Irwansyah², Niken Febrina Ernungtyas', Syahrul Hidayanto1 \\ 'Sekolah Tinggi Ilmu Komunikasi InterStudi \\ ${ }^{2}$ Departemen IImu Komunikasi, Fakultas IImu Sosial dan IImu Politik, Universitas Indonesia \\ Email: ardianto1220@gmail.com, guntur@stikom.interstudi.edu, irwansyah09@ui.ac.id, niken@ \\ stikom.interstudi.edu, syahrul.hidayanto1@gmail.com
}

\begin{abstract}
ABSTRAK
Lobi dan negosiasi sebagai kegiatan komunikasi sampai saat ini masih dianggap memiliki asosiasi yang negatif. Padahal, dua kegiatan tersebut dapat berdampak positif misalnya membantu legislator meyakinkan pemangku kepentingan untuk mengesahkan Rancangan Undang-Undang (RUU) yang bermanfaat bagi masyarakat luas. Tujuan penelitian ini adalah untuk memahami praktik dan lobi yang dilakukan anggota legislatif kepada pemangku kepentingan dalam proses pembahasan RUU Konsultan Pajak. Penelitian ini menggunakan pendekatan kualitatif, strategi penelitian studi kasus, dan pengumpulan data berupa wawancara terstruktur dan dokumentasi. Data penelitian dianalisis menggunakan analisis tematik dan triangulasi penelitian berupa triangulasi teori dan data. Hasil penelitian menunjukkan bahwa dalam melakukan praktik lobi dan negosiasi, legislator sebagai komunikator politik menempatkan posisi sebagai politisi partisan. Lima area dasar kegiatan lobi yang dilakukan yaitu menjalin koalisi dengan organisasi berpengaruh di luar DPR, melakukan riset dan laporan, menjalin komunikasi dengan individu di dalam parlemen, memilih pembicara dan saksi ahli, serta melakukan persiapan debat. Sementara, bentuk kegiatan komunikasi dalam proses negosiasi yaitu mengonstruksi narasi, menetapkan strategi negosiasi, dan mengelola hubungan dengan konstituen. Meskipun proses lobi dan negosiasi menemui gangguan, legislator ternyata berhasil meyakinkan para pemangku kepentingan untuk menyetujui RUU Konsultan Pajak masuk dalam daftar Prolegnas Prioritas tahun 2018.
\end{abstract}

Kata kunci: lobi, negosiasi, komunikator politik, legislator, konsultan pajak

\begin{abstract}
Lobbying and negotiation as a communication activity are still considered to have a negative association. In fact, these two activities can have a positive impact, for example helping legislators convince stakeholders to pass the Draft Law (RUU) that is beneficial to the wider community. The purpose of this study is to understand the practices and lobbying of legislative members to stakeholders in the discussion process of the Draft Law on Tax Consultants. This study uses a qualitative approach, case study research strategies, and data collection in the form of structured interviews and documentation. The research data were analyzed using thematic analysis and research triangulation in the form of theory and data triangulation. The results showed that in conducting lobbying and negotiation practices, legislators as political communicators placed positions as partisan politicians. The five basic areas of lobbying are coalitioning with influential organizations outside the DPR, conducting research and reports, establishing communication with individuals in parliament, selecting speakers and expert witnesses, and preparing for debate. Meanwhile, the form of communication activities in the negotiation process is constructing the narrative, setting negotiation strategies, and managing relations with constituents. Even though the lobbying and negotiation process met with disruption, the legislator was successful in convincing the
\end{abstract}


stakeholders to approve the Draft Law on Tax Consultants being included in the 2018 Priority Prolegnas list.

Keywords: lobbying, negotiation, political communicators, legislators, tax consultants

\section{A. PENDAHULUAN}

Praktik lobi dan negosiasi oleh pejabat pemerintah sudah menjadi hal yang lumrah untuk ditemui di berbagai negara di dunia. Misalnya saja, pertemuan yang dilakukan oleh Presiden Amerika Serikat, Donald Trump dengan Presiden Korea Utara, Kim Jong-un di Singapura tahun 2018 lalu. Dalam pertemuan itu, Presiden Trump berjanji menunda latihan militer bersama dengan Korea Selatan sebagai imbalan atas komitmen Korea Utara melakukan denuklirisasi. Pertemuan tersebut berakhir dengan jabat tangan sebagai tanda mencairnya hubungan antara kedua negara (Shonk, 2018). Sementara, contoh kasus di Indonesia yaitu perebutan kembali Irian Barat (saat ini Papua) dari Belanda pada 1 Mei 1963 karena suksesnya lobi-lobi yang dilakukan tokoh Indonesia yang berpengaruh di dunia internasional. Kala itu, diplomat Indonesia mampu melakukan lobi kepada banyak pemimpin dunia untuk menekan Belanda agar mengakui kedaulatan Indonesia di Irian Barat (Fauzan, 2015).

Menurut Joos (2011), lobi atau representasi kepentingan erat kaitannya dengan politisi atau otoritas administratif yang biasanya menyasar kelompok tertentu. Lobi bertujuan untuk mendapatkan pengaruh yang pasti dan seolah-olah hampir bisa diukur pada keputusan politik tertentu. Jika lobi membahas konten yang cenderung sensitif, maka kerahasiaan dan kebijaksanaan menjadi penting. Lobi dapat dikatakan sukses jika perencanaan di awal cukup terperinci dan orang yang melakukan lobi harus memiliki pengetahuan mendalam tentang arena politik.

Sementara, negosisasi diartikan sebagai salah satu pendekatan untuk mengelola konflik dalam seting antarpribadi, kelompok, organisasi, masyarakat, dan internasional. Negosiasi dimaksudkan untuk mengurangi perbedaan di antara ketidakcocokan dan berakhir dengan sebuah kesepakatan. Negosiasi dapat ditemukan dalam banyak seting sosial seperti transaksi pembeli-penjual, transaksi bisnis, pekerjamanajemen, hubungan pernikahan, situasi penyanderaan dan sebagainya. Pendekatan komunikatif pada negosiasi berfokus pada elemen interaktif dalam proses negosiasi seperti simbol, pesan, dan bahasa yang digunakan untuk menyusun rencana, membingkai masalah, dan membujuk orang lain dalam proses mencapai kesepakatan (Barge, 2009).

Lobi selama ini dianggap memiliki asosiasi yang negatif baik di media maupun masyarakat umum. Lobi sering disalah artikan sebagai representasi sepihak kepentingan bisnis kepada orang lain. Lobi dinilai tidak menguntungkan, serba rahasia, atau bahkan dikaitkan dengan tindakan korupsi dan nepotisme (Joos, 2011). Maka dari itu, lobi kerap dihindari karena dianggap mampu mengurangi sahnya negosiasi. Padahal, lobi dan negosiasi saling terkoneksi satu sama lain. Melalui lobi yang efektif, negosiasi dapat dipastikan berjalan dengan sukses (Fauzan, 2015).

Dalam komunikasi politik, lobi politik dan retorika negosiasi sebaiknya dilakukan secara face to face dan door to door. Keduanya membutuhkan ruang yang lebih personal agar tujuan mempersuasi lebih dalam dapat dimungkinkan sehingga terjadi dialog dan kompromi. Komunikasi politik melalui antarpersonal dapat dimulai melalui percakapan telepon, chatting, dan berujung dengan pertemuan tatap muka. Bahasa dan retorika yang baik dalam hal ini menjadi perlu diperhatikan. Retorika bertujuan memengaruhi tiap pribadi individu mengambil sikap secara pribadi tanpa dipengaruhi oleh orang yang berada disekitarnya. Retorika juga dapat menciptakan negosiasi yang berlangsung secara berkelanjutan (Shahreza, 2018). 
Di Indonesia, salah satu kasus yang berhubungan dengan praktik lobi dan negosiasi yang sempat menjadi sorotan media massa adalah masuknya Rancangan Undang-Undang (RUU) Konsultan Pajak dalam penyusunan Program Legislasi Nasional (Prolegnas) di Dewan Perwakilan Rakyat (DPR). Prolegnas adalah instrumen perencanaan program pembentukan UU yang disusun secara berencana, terpadu, dan sistematis (DPR RI, 2004). RUU Konsultan Pajak berhasil masuk ke dalam daftar Prolegnas Prioritas Tahun 2018 mengalahkan sekian banyak usulan RUU. Keberhasilan masuknya RUU Konsultan Pajak diklaim berkat lobi dan negosiasi yang dilakukan anggota DPR kepada pemangku kepentingan (stakeholder) yaitu Badan Legislasi (Baleg) DPR, Dewan Perwakilan Daerah (DPD), dan Pemerintah.

Baleg DPR mengungkapkan bahwa tujuan utama RUU Konsultan Pajak adalah meningkatkan penerimaan pajak negara. Selain itu, RUU ini bisa memberikan edukasi kemudahan pelayanan di bidang perpajakan kepada para wajib pajak. RUU Konsultan Pajak juga membahas sifat profesi konsultan pajak di masa mendatang, apakah bersifat terbuka atau tertutup (Badan Legislasi DPR RI, 2018). Proses masuknya RUU Konsultan Pajak ke dalam daftar Prolegnas Prioritas Tahun 2018 memang tidak berjalan mulus. RUU ini pun sempat menuai polemik di kalangan praktisi perpajakan dan akademisi karena dianggap hanya merujuk pada satu asosiasi saja sehingga terkesan monopolistik. Selain itu, RUU ini dinilai dapat mendegradasi peran negara (Suwiknyo, 2018).

Meskipun sempat menuai polemik, faktanya RUU Konsultan Pajak berhasil masuk daftar Prolegnas Prioritas Tahun 2018. Di balik keberhasilannya, tentu ada praktik lobi dan negosiasi oleh pihak yang berkepentingan. Tentu tidaklah mudah mengawal RUU Konsultan Pajak mengingat panjangnya proses penetapan Prolegnas yang dimulai dari penyusunan, pembahasan, dan penetapan Prolegnas yang dilakukan bersama Baleg DPR, DPD, dan Pemerintah.
Penelitian ini penting karena bertujuan untuk memahami bagaimana pelobi (dalam konteks penelitian ini adalah legislator) melakukan lobi dan negosiasi berdasarkan pendekatan komunikasi sehingga berhasil meloloskan RUU Konsultan Pajak ke dalam Prolegnas Prioritas Tahun 2018.

\section{B. TINJAUAN PUSTAKA}

\section{Elemen Komunikator Politik}

Setiap orang memiliki hak untuk berkomunikasi tentang politik. Namun, yang melakukan kegiatan tersebut secara konsisten masih relatif sedikit. Padahal, komunikator politik memiliki andil besar dalam proses pembuatan opini publik (Shahreza, 2018). Doob (1948) menjelaskan bahwa politisi, profesional, dan aktivis dapat disebut sebagai komunikator utama dalam politik. Komunikator politik berasal dari kombinasi beragam profesi yang memiliki latar belakang yang berbeda. Misalnya perpaduan militer dan akademisi, ilmuan dan sipil, ulama, hingga pengusaha. Shahreza (2018) menyebut komponen komunikator politik adalah elit yang berasal dari berbagai bidang. Elit yang dimaksud di sini adalah orang-orang terbaik/orang-orang pilihan dalam sebuah kelompok. Mereka biasanya menempati posisi teratas dalam institusi ekonomi, politik, ataupun militer.

Menurut Katz (1960), politisi dapat dibedakan menjadi dua berdasarkan orientasi kepentingan politisi pada proses politik. Dua jenis politisi tersebut yaitu politisi ideologi yang juga dikenal dengan istilah negarawan dan politisi partisan. Orang-orang yang dalam proses politik memperjuangan dan mementingkan kepentingan bersama disebut sebagai politisi ideolog. Mereka yang termasuk ke dalam politisi jenis ini mengedepankan reformasi, revolusi, dan tidak memiliki tanggung jawab untuk mengikuti tuntutan pengikut atau kelompoknya. Sedangkan, orang-orang yang dalam proses politik selalu memperjuangkan kepentingan pengikut atau kelompoknya disebut politisi partisan (Doob, 1948; Nimmo, 2006). 
Profesional sebagai komunikator politik utamayang lain merupakan peran sosialyang baru yang kemunculannya dilatarbelakangi dengan hadirnya media massa dan media khusus (majalah khusus, radio khusus, dan sebagainya). Media massa dan media khusus dikenal sbagai tempat pembentukan serta pengelolaan simbol dan khalayak khusus. Berdasarkan hal tersebut, komunikator profesional lantas diperlukan karena dinilai memiliki keterampilan dalam mengelola simbol-simbol dan lihai menghubungkan orang-orang atau kelompok yang memiliki perbedaan (Doob, 1948; Nimmo, 2006).

Carey (1965) menyebut komunikator profesional sebagai makelar simbol karena keahliannya menerjemahkan pengetahuan suatu komunitas ke dalam istilah komunitas lain yang jelas dan mudah dimengerti. Profesional juga terbagi menjadi dua jenis yaitu jurnalis dan promotor. Tugas utama jurnalis adalah mencari, mengolah, dan memublikasikan berita kepada khalayak. Sebagai profesional, jurnalis mampu melakukan framing, agenda setting, menghubungkan politisi dengan publik, hingga menghubungkan publik dengan pemimpin. Sementara promotor adalah orang yang disewa oleh kandidat atau partai politik untuk melakukan pemasaran politik seperti kampanye politik atau orang yang bertugas sebagai Public Relations politik yang memikirkan strategi branding dan menjaga nama baik client mereka. Lewat keahliannya, promotor bisa memanipulasi, menginterpretasi, dan menghubungkan client dengan khalayak. Contoh promotor yaitu konsultan politik partai tertentu dan pengamat politik yang argumennya dibeli oleh kelompok tertentu (Doob, 1948; Nimmo, 2006).

Terakhir, aktivis adalah komunikator politik yang begerak melalui saluran organisasional dan interpersonal. Aktivis terbagi menjadi dua yaitu jurubicara dan pemuka pendapat. Jurubicara bergerak melalui saluran organisasi dan mengedepankan kepentingan organisasi. Jurubicara biasanya kurang tertarik masuk ke jalur politik karena umumnya orang yang termasuk ke dalam jurubicara tidak mendambakan sebuah jabatan. Meskipun biasanya bukan profesional dalam komunikasi, namun jurubicara cukup terlibat baik dalam politik dan semiprofesional komunikasi politik. Selanjutnya pemuka pendapat yang bergerak lewat saluran interpersonal. Pemuka pendapat adalah orang yang dimintai petunjuk dan informasi oleh orang-orang. Pemuka pendapat biasanya dihormati dan mampu memengaruhi keputusan orang. Pemuka pendapat juga pandai meyakinkan orang lain terhadap gagasannya. Mereka juga memiliki tanggung jawab meneruskan berita politik dari media massa kepada masyarakat umum (Doob, 1948; Nimmo, 2006).

\section{Konseptualisasi Lobi}

Menurut Zorack (1990) lobi akan selalu menjadi bagian dari sistem politik dan legislatif sebuah negara. Zorack (1990) menjelaskan, istilah lobi telah banyak didefinisikan dengan berbagai cara, tetapi pada dasarnya lobi adalah hak setiap warga negara atau kelompok kepentingan untuk mengajukan petisi kepada pemerintah atau kongres dan memberikan informasi yang dirancang untuk memengaruhi bagian atau menggagalkan undang-undang. Definisi lobi yang lain adalah upaya yang disengaja untuk mempengaruhi keputusan politik melalui berbagai bentuk advokasi yang diarahkan pada pembuat kebijakan atas nama orang lain, organisasi, atau kelompok (Arroyo et al., 2002). Sementara, Edgett (2002) menawarkan definisi lobi yang lebih sederhana yaitu lobi sebagai tindakan yang secara terbuka mewakili individu, organisasi atau ide dengan tujuan membujuk audiens yang ditargetkan untuk memandang positif - atau menerima sudut pandang - individu, organisasi, atau ide.

Pada tahun 1960, Lester Milbrath yang disebut sebagai bapak penelitian lobi, menganalisis lobi dari perspektif komunikasi (Berg,2009; Koeppl,2000). MenurutMilbrath (1960), komunikasi menjadi satu-satunya cara untuk memengaruhi atau mengubah persepsi. Maka dari itu, tidak salah jika proses lobi sepenuhnya merupakan proses 
komunikasi. Dondero \& Lunch (2005) juga menulis lobi sebagai proses komunikasi dua arah. Mereka menggambarkan pelobi sebagai komunikator yang hebat. Menurut Dondero dan Lunch (2005), pelobi melakukan tiga fungsi utama di arena legislatif: 1) menyebarluaskan informasi yang diperlukan untuk menyusun undangundang 2) mengumpulkan opini publik tentang isu-isu utama, dan 3) membantu mengatur agenda politik dengan menciptakan koalisi untuk mendukung atau menentang RUU tertentu. Akibatnya, pelobi adalah mata dan telinga publik, penyedia informasi, perwakilan klien dan konstituen mereka, pembentuk agenda pemerintah, penggerak legislasi, pembangun koalisi, dan kontributor kampanye (Berg, 2009; Dondero \& Lunch, 2005).

Menurut Grunig \& Hunt (1984) ada lima kelompok khusus kegiatan lobi yaitu: (1) pembentukan koalisi, (2) penelitian dan laporan, (3) kontak dengan individu/ kelompok yang berpengaruh, menyiapkan pembicara dan saksi ahli, dan (5) fokus dalam debat. Grunig \& Hunt (1984) menjelaskan agar melobi dapat lebih berhasil, maka seseorang perlu untuk terhubung dengan kelompok yang memiliki tujuan yang sama dengannya. Membuat koalisi memang bisa sangat rumit, karena jarang sekali ditemukan dua kelompok dengan minat dan tujuan yang persis sama. Namun, jika koalisi berjalan dengan mulus, maka peluang keberhasilan melobi juga lebih besar.

Selanjutnya, dibutuhkan penelitian dan laporan sebelum melakukan lobi. Sebaiknya siapkan laporan dan dokumen pendukung karena akan sangat membantu legislator dalam membuat keputusan yang tepat. Kemudian, setelah membentuk koalisi dan melakukan penelitian dan persiapan, kegiatan selanjutnya adalah menghubungi individu/kelompok yang berpengaruh. Setiap badan legislatif terdiri dari sejumlah besar individu. Tugas pelobi adalah mengidentifikasi siapa di antara mereka yang memiliki dampak besar pada yang lain, yang mendominasi dalam diskusi langsung dan siapa di antara mereka yang memiliki minat khusus dalam penerapan undangundang dan peraturan tertentu (Grunig \& Hunt, 1984).

Mempersiapkan pembicara dan saksi ahli juga menjadi hal yang umum dalam lobi. Jika dibutuhkan, pembicara dapat mengikuti pelatihan untuk penampilan publik mereka atau kontak dengan pembuat keputusan utama. Kegiatan terakhir dari melobi adalah memfokuskan perdebatan. Ini merujuk pada upaya pelobi untuk memusatkan perhatian dan minat legislator pada fakta yang dapat mengarah pada penerimaan sikap atau pandangan klien mereka (Grunig \& Hunt, 1984).

\section{Konseptualisasi Negosiasi}

Negosiasi adalah dialog antara dua orang atau lebih, yang dimaksudkan untuk mencapai pemahaman, menyelesaikan perbedaan, atau mendapatkan keuntungan dalam hasil dialog, untuk menghasilkan kesepakatan tentang tindakan, untuk tawarmenawar demi keuntungan individu atau kolektif dan untuk memenuhi berbagai kepentingan dari dua pihak yang terlibat dalam proses negosiasi. Negosiasi memang dimaksudkan untuk mengarah pada kompromi. Negosiasi dapat kita temui dalam dunia bisnis, organisasi nirlaba dan cabang pemerintah, proses hukum, di antara negara-negara dan dalam situasi pribadi seperti pernikahan, perceraian, pengasuhan anak, dan kehidupan seharihari (Čulo \& Skendrović, 2012).

Thompson, Ebner, \& Giddings (2017) mengatakan jika kekuatan negosiasi tidak hanya bergantung pada verbal saja tetapi juga non verbal. Negosiasi bahkan digambarkan sebagai komunikasi yang lebih besar dari kehidupan di mana setiap hal yang dilakukan dan tidak dilakukan mengirimkan sinyal ke negosiator lain. Bahasa tubuh dan bentuk komunikasi visual lainnya seperti penampilan, pakaian, postur, gaya berjalan, simbol lingkungan fisik dan penggunaan alat bantu visual (bagan, diagram, dan sebagainya) dapat bervariasi dampaknya tergantung pada norma budaya (Alexander, Howieson, \& Fox, 2015). Dalam negosiasi, masing-masing pihak menggunakan 
taktiknya sendiri dengan tujuan mencapai hasil maksimal. Risiko dalam melakukan negosiasi adalah bahwa tidak ada jaminan hasil yang sukses dan seringkali harapan para pihak memengaruhi taktik mereka dan hasil negosiasi (Zohar, 2015)to reach a successful conclusion, are particularly critical in international conflicts. Negotiation skills are important to achieve agreements in business. Yet the importance effective negotiation is not limited to international treaties or crises. The ability to negotiate is valuable to business managers because the skills developed through practicing negotiation skills develop critical thinking aptitudes and effective communication skills (McClendon, 2009.

Sebagian orang memiliki asumsi yang keliru bahwa tidak ada yang bisa dinegosiasikan kecuali ada salah satu pihak yang menemui sebuah masalah. Padahal, negosiasi tidak selalu terwujud ketika ditemukan sebuah masalah. Pandangan yang realistis adalah semuanya dapat dinegosiasikan karena negosiasi erat kaitannya dengan kepentingan. Sepertiyang dikatakan oleh Shell (2006) yang dengan sederhana mendefinisikan negosiasi sebagai proses komunikasi interaktif yang terjadi setiap kali kita menginginkan sesuatu dari orang lain atau orang lain menginginkan sesuatu dari kita.

\section{Negosiasi dan Komunikasi}

Barge (2009) menjelaskan bahwa terdapat tiga kegiatan komunikasi yang penting dan saling berkaitan dalam konsep negosiasi yaitu membingkai (framing), menyusun strategi, dan mengelola hubungan. Ketiga dimensi akan dijelaskan sebagai berikut: (1) Kegiatan pembingkaian dalam negosiasi adalah mengeksplorasi melalui visi, perspektif, atau pendirian seseorang atau menciptakan pengaruh melalui bagaimana mereka memahami situasi dan menciptakan posisi tawar. Menurut Barge (2009) kerangka yang bisa dipakai untuk memengaruhi seseorang adalah dengan melihat sesuatu berdasarkan nilai untung atau rugi, menganggap pesan atau ide sebagai persaingan atau kerja sama, mengidentifikasi alasan dan motif dibalik pesan atau ide yang dibuat seseorang sah atau tidak, apakah mereka menanggapi langkah pihak lain menggunakan strategi dan taktik distributif atau integratif, dan apakah mereka cenderung menerima tawaran atau tidak. Mekanisme kognitif dalam hal ini dibutuhkan sebagai filter persepsi yang dapat memengaruhi cara individu memahami konteks negosiasi serta memengaruhi aktivitas seperti mencari informasi dan memilih strategi. Barge (2009) menjelaskan beberapa ahli teori komunikasi telah mengeksplorasi bagaimana pengembangan isu dikonstruksikan melalui argumen, narasi, justifikasi, hingga pembuatan kasus.

(2) Penyusunan strategi mengacu pada strategi kinerja komunikatif dan taktik selama negosiasi. Strategi merujuk pada rencana luas yang mencakup serangkaian gerakan, sementara taktik adalah pesan khusus yang menjalankan gerakan. Barge (2009) mencontohkan, bisa saja seseorang memiliki strategi integratif namun pada berbagai titik selama negosiasi, ia bergantung ada taktik distributif guna mencapai keseluruhan strategi integratif. Secara umum, terdapat tiga model strategi yaitu dominan, campuran dan episodik. Model strategi dominan mengasumsikan bahwa proses negosiasi stabil dari waktu ke waktu dan bahwa negosiator secara konsisten menggunakan strategi distributif atau integratif selama negosiasi. Sementara, model strategi campuran memungkinkan variabilitas strategi karena negosiator dapat mengubah strategi mereka selama negosiasi. Kemudian, model negosiasi episodik mengasumsikan bahwa negosiasi terungkap dari waktu ke waktu dan bahwa negosiator dapat mengubah strategi mereka sesuai dengan tahap perkembangan negosiasi atau karakteristik khusus dari episode.

(3) Mengelola hubungan mengacu pada cara-cara negosiator mengelola hubungan dengan konstituen mereka. Terdapat perbedaan antara agen, konstituen, dan khalayak dalam teori negosiasi. Negosiator biasanya bertindak sebagai 
agen yang mewakili posisi dan kepentingan konstituen tertentu. Sebagai contoh, selama negosiasi terkait tenaga kerja, negosiator berfungsi sebagai agen untuk konstituen utama mereka yaitu serikat pekerja atau perusahaan (Barge, 2009).

\section{Kerangka Konseptual}

Kerangka konseptual yang dapat dilihat pada Gambar 1 menjelaskan bahwa lobi dan negosiasi dilakukan oleh komunikator politik yang dalam konteks penelitian ini adalah anggota legislatif (DPR) yang memiliki kepentingan tertentu. Seperti yang telah di jelaskan di atas, lobi memiliki lima kegiatan khusus yaitu pembentukan koalisi, penelitian dan persiapan, kontak dengan individu/kelompok yang berpengaruh, persiapan pembicara, dan fokus dalam debat (Grunig \& Hunt, 1984).

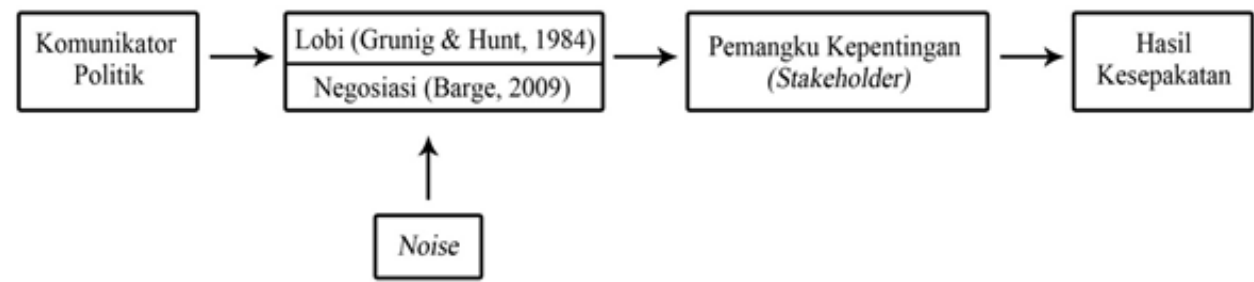

Gambar 1. Kerangka Konseptual Praktik Lobi \& Negosiasi oleh Komunikator Politik

Sementara, negosiasi yang dilihat dengan pendekatan komunikasi, memiliki tiga kegiatan komunikasi yang penting dan saling berkaitan yaitu membingkai (framing), menyusun strategi, dan mengelola hubungan (Barge, 2009).

Lobi dan negosiasi yang dilakukan oleh komunikator politik menyasar pemangku kepentingan (stakeholder) yang dalam konteks penelitian ini terdiri dari Baleg DPR, DPD, dan Pemerintah. Proses melakukan lobi dan negosiasi tentu tidak selamanya berjalan mulus. Bisa saja terdapat noise atau gangguan yang berasal dari pihak-pihak yang merasa dirugikan. Untuk itu, keahlian komunikator politik untuk menghilangkan gangguan di sini menjadi fokus yang penting. Proses lobi dan negosiasi dianggap telah selesai jika telah menemui hasil kesepakatan yang diinginkan.

\section{METODE PENELITIAN}

Pendekatan penelitian yang dipilih adalah kualitatif yang menekankan pada cara orang menafsirkan dan memahami pengalaman realitas sosial individu (Mohajan, 2018). Metode kualitatif digunakan untuk menjawab pertanyaan tentang pengalaman, makna dan perspektif, paling sering dari sudut pandang informan. Data-data kualitatif biasanya tidak dapat dihitung atau diukur (Hammarberg, Kirkman, \& de Lacey, 2016).

Penelitian ini menggunakan strategi penelitian studi kasus yaitu terpilihnya RUU Konsultan Pajak ke dalam daftar Prolegnas tahun 2018.

RUU Konsultan Pajak merupakan inisiatif DPR yang diharapkan dapat menjadi landasan hukum yang kuat bagi profesi konsultan pajak sekaligus mampu menyelaraskan pengaturan profesi konsultan pajak di negara lain setingkat undang-undang (Barus, 2018). Kasus ini menjadi menarik karena menuai polemik di kalangan akademisi dan praktisi perpajakan karena dinilai hanya menguntungkan satu asosiasi profesi dan mendagradasi peran pemerintah (Suwiknyo, 2018).

Alat pengumpulan data berupa wawancara terstruktur dan studi dokumentasi. Informan dipilih secara sengaja dengan pertimbangan dapat memberikan informasi yang relevan dengan tujuan penelitian. Wawancara pertama dilakukan bersama salah satu anggota Komisi XI DPR RI, Mukhamad Misbakhun (MM) yang sangat vokal mendukung RUU Konsultan Pajak masuk ke dalam daftar Prolegnas 2018. Namanyajuga sering dikutip oleh banyak 
media massa yang memberitakan RUU Konsultan Pajak. Peneliti juga melakukan wawancara dengan Ketua Umum Ikatan Konsultan Pajak Indonesia (IKPI), Mochamad Soebakir (MS). IKPI dianggap menjadi salah satu oganisasi yang diuntungkan ketika UU Konsultan Pajak nantinya disahkan.

Selain wawancara terstruktur, studi dokumentasi juga dilakukan dengan mengumpulkan dokumen elektronik dari media massa dan Portal Berita Baleg DPR selama periode tahun 2018. Data penelitian yang terkumpul kemudian dianalisis menggunakan analisis tematik yang merupakan metode menganalisis, mengidentifikasi, dan melaporkan pola (tema) dalam data. Analisis tematik ditempuh dengan serangkaian tahap seperti compiling, disassembling, reassembling, interpreting, dan concluding (Castleberry \& Nolen, 2018). Kemudian, triangulasi penelitian juga dibutuhkan. Dalam penelitian ini triangulasi yang digunakan berupa triangulasi teori dan data.

\section{TEMUAN DAN BAHASAN}

\section{Komunikator Politik: Politisi Partisan dan Kepentingan Partai}

Jika mengacu pada konsep Katz (1960), dalam kasus RUU Konsultan Pajak, MM menempatkan posisinya sebagai politisi partisan. Meskipun MM membangun narasi bahwa RUU Konsultan Pajak mengamankan penerimaan pajak dan menjaga hak-hak para wajib pajak, akan tetapi di sisi lain ia memperjuangkan kepentingan kelompok tertentu yang dinilai oleh pihak kontra RUU Konsultan Pajak terlalu monopolistik. Politisi partisan memang sering dikaitkan dengan keberpihakannya terhadap kepentingan partai. Maka tidak salah jika dikatakan bahwa politisi partisan menggambarkan partai. Jika mesin kekuatan partai tidak cukup, maka politisi akan mengajak mereka yang berada di luar partai untuk bersekutu dan membantu menyebarluaskan agenda partai kepada masyarakat yang lebih luas. Mereka inilah yang kemudian disebut sebagai partisan partai politik (Henry, Lawrence, \& Sides, 2010; White \& Ypi, 2016).

Partai Golkar sebagai pengusul RUU Konsultan Pajak, sedariawal memang diminta Presiden Joko Widodo untuk membantu memperkuat upaya pemerintahannya dalam mereformasi sektor perpajakan. Salah satu langkah yang kemudian diwujudkan oleh Partai Golkar adalah dengan menjadi inisiator RUU Konsultan Pajak (Ryandi, 2018). Terlepas bahwa apakah UU Konsultan Pajak nantinya akan memberikan dampak positif kepada masyarakat, perlu diketahui bahwa, Partai Golkar memiliki kepentingan utama yaitu untuk menjalankan tugasnya sebagai koalisi partai politik pendukung pemerintah.

\section{Rekam Jejak RUU Konsultan Pajak}

Berdasarkan situs dpr.go.id, RUU Konsultan Pajak pertama kali diinisiasi pada tahun 2016 oleh Fraksi Partai Golongan Karya (Golkar). Pada September 2017, RUU ini masuk ke dalam Prolegnas Perubahan 2017. Dua bulan setelahnya, RUU Konsultan Pajak mulai dibahas lebih lanjut dan masuk ke dalam daftar Prolegnas 2018. Pada Mei 2018, RUU Konsultan Pajak sudah berada dalam tahap harmonisasi dengan Baleg DPR. Kemudian, pada bulan Juli 2018, Baleg DPR meloloskan RUU Konsultan Pajak dan menyepakati 13 poin dalam RUU tersebut. Pada November 2018, RUU Konsultan Pajak berubah status menjadi pembahasan tingkat pertama. Di tahun 2019, RUU Konsultan Pajak ditargetkan segara rampung kemudian disahkan menjadi UU. Namun, perkembangan terakhir menunjukan bahwa RUU ini masih butuh dibahas lebih lanjut dengan terdaftarnya RUU ini pada Prolegnas 2020-2024 (DPR Rl, 2016, 2020c; Hidayat, 2018; Setiawan, 2018; Sukarelawati, 2019).

RUU Konsultan Pajak terdiri atas 14 bab, 35 pasal, dan 25 ayat. RUU ini mengatur definisi konsultan pajak, konsultan pajak asing di Indonesia, praktik penyelenggaraan konsultan pajak, kode etik, tingkatan konsultan pajak, hak dan kewajiban, organisasi konsultan pajak hingga ketentuan pidana yang berkaitan dengan konsultan 
pajak (DPR RI, 2020b). MM sebagai salah satu legislator dan inisiator RUU Konsultan Pajak mengatakan bahwa RUU ini sangat diperlukan oleh para konsultan pajak dalam rangka kontribusi dan prestasi mereka dalam membantu masyarakat Indonesia untuk mengamankan penerimaan pajak.

"Saya menginisasi UU ini dalam rangka untuk memberikan penggiatan kepada profesi konsultan pajak di Indonesia, sebagai tuan rumah bagi pangsa pasar jasa konsultan pajak di Indonesia. Ini adalah kepentingan nasional yang harus dijaga oleh para pembuat UU. Keberpihakan ini harus nyata dalam bentuk UU. Konsultan pajak harus diatur dalam tingkat UU," (MM)

MM juga menuturkan bahwa pajak termasuk dalam tulang punggung sumber pembiayaan keuangan negara. Untuk itu, pajak sudah pasti menjadi kepentingan nasional. Lewat konsultan pajak, mereka dapat menjaga hak-hak para wajib pajak. Namun sayangnya, belum ada UU yang mengatur profesi konsultan pajak. Maka dari itu, MM bersikeras agar RUU tersebut dapat segera disahkan.

"Penerimaan pajak kita adalah salah satu tulang punggung utama sumber pembiayaan APBN kita, pembangunan nasional. Menggaji polisi, TNI, Guru, biaya operasional skala, memperbaiki jalanan, bagaimana listrik tetap menyala, untuk masyarakat miskin, pelayanan kesehatan, BPJS dan sebagainya. Semuanya sumber dan muara yang paling besar itu berasal dari pajak. Akuntan, arsitek, ASN, Polri punya undang-undang, tetapi profesi konsultan pajak belum. Maka profesi konsultan pajak ini juga harus diregulasi pada tingkatan undang-undang," (MM)

Konsultan pajak memiliki peran strategis sebagai penghubung antara wajib pak dengan Direktorat Jenderal Pajak (Ditjen Pajak). Konsultan pajak bukan hanya menjual jasa konsultasi dan mengurusi perpajakan, akan tetapi juga mendampingi wajib pajak menjalani pemeriksaan pajak, mengajukan banding dan keberatan terkait tindak pidana perpajakan dan sebagainya. Sayangnya, profesi ini belum diatur oleh UU. Profesi konsultan pajak sampai saat ini hanya diatur oleh Peraturan Menteri Keuangan. Alasan Inilah yang melatarbelakangi DPR menginisiasi RUU Konsultan Pajak (Ortax. org, 2018).

\section{Proses Lobi dan Negosiasi di DPR}

Ketika melakukan lobi kepada pemangku kepentingan, MM memang tidak bekerja sendiri. la merangkul IKPI, sebagai organisasi yang juga mendapatkan keuntungan jika RUU Konsultan Pajak disahkan oleh pemerintah. IKPI mendukung secara penuh inisiasi RUU tersebut. Bentuk dukungan IKPI berupa mengadakan seminar nasional di beberapa tempat tentang RUU Konsultan Pajak, melakukan publikasi media, memberikan masukan terkait usulan substansi RUU, dan menjalin komunikasi dengan pemangku kepentingan.

"IKPI berhubungan baik dengan DPR terutama dengan Bapak M Misbakhun selaku Pengusul RUU Konsultan Pajak di DPR. IKPI senantiasa menjalin hubungan dan komunikasi dengan stakeholder yang secara langsung berkepentingan dengan adanya UU Konsultan Pajak seperti Kementerian Keuangan, Direktorat Jendral Pajak, Asosiasi Dunia Usaha (KADIN, HIPMI, APINDO), masyarakat wajib pajak (Asosiasi industri) dan Media Massa untuk memberikan sosialiasi," (MS)

Dalam melakukan lobi, pelobi memang harus menjalin hubungan yang baik dengan kelompok yang memiliki kepentingan yang sama dengannya. Mengajak kelompok untuk menjadi mitra koalisi memang rumit apalagi jika kelompok tersebut memiliki kepentingan yang tumpang tindih (Grunig \& Hunt, 1984). Dalam kasus RUU Konsultan Pajak, selama proses pembahasan RUU, IKPI tidak pernah berlawanan pendapat dengan MM selaku pelobi. Alhasil, koalisi dapat berjalan dengan baik dan MM selalu mendapatkan kepercayaan dari IKPI. Peran IKPI sebagai mitra koalisi MM, memang cukup berpengaruh dalam proses 
pembahasan RUU. IKPI sangat kooperatif ketika memberikan masukan mengenai substansi RUU. Hubungan IKPI dengan media massa juga dapat dikatakan baik karena minimnya pemberitaan negatif.

"IKPI mengerti dengan baik dan mengerti dengan sangat dalam bahwa profesi ini sangat strategis dalam upaya membantu negara untuk meningkatkan penerimaan pajak," (MM)

Kemudian, MM sebagai komunikator politik dan IKPI sebagai mitra koalisi juga bersama-sama melakukan penelitian dan menyiapkan laporan yang cukup matang. MM beberapa kali mendatangi universitas ataupun menggelar diskusi publik untuk menerima masukan terkait RUU Konsultan Pajak. Berdasarkan data yang dimiliki IKPI, Indonesia memang masih tertinggal dari negara lain seperti Jepang terkait jumlah konsultan pajak. Indonesia yang jumlah penduduknya lebih dari 250 juta jiwa hanya memiliki 4.500 konsultan pajak. Sedangkan Jepang, memiliki 66.000 pegawai pajak dan 74.000 konsultan pajak dengan jumlah penduduknya yang lebih kecil dibanding Indonesia (Sukarelawati, 2019). Lewat RUU tersebut diharapkan jumlah konsultan pajak dapat bertambah karena adanya kejelasan hukum yang mengatur profesi tersebut. Hasil riset inilah yang sering digaungkan oleh MM saat rapat pembahasan RUU Konsultan Pajak di DPR dan seminar nasional di beberapa tempat di Indonesia dengan maksud menekankan urgensi RUU tersebut. Hasil riset dan laporan yang diberikan kepada pemangku kepentingan dapat memancing diskusi pada rapat pembahasan. Pelobi dapat menunjukan hasil riset dan laporan yang mendukung disahkannya RUU yang diusulkan. Jika diperlukan, pelobi dapat bekerja sama dengan akademisi atau lembaga riset profesional.

Setelah koalisi terbentuk dan hasil riset dan laporan telah disiapkan, kegiatan selanjutnya adalah menjalin komunikasi dengan individu atau kelompok yang berpengaruh. Fraksi Partai Golkar sebagai inisiator RUU Konsultan Pajak memang cukup berhasil menjalin kontak dengan individu atau kelompok berpengaruh di DPR. Dalam rapat mendengarkan laporan Panitia Kerja (Panja) terkait RUU Konsultan Pajak pada Juli 2018, mayoritas fraksi partai merespon positif usulan RUU Konsultan Pajak. Hasil rapat tersebut menyimpulkan bahwa RUU Konsultan Pajak direstui Baleg DPR untuk dilanjutkan pembahasannya (Setiawan, 2018). Saat menjalin komunikasi dengan anggota legislatif dari fraksi partai lain, pelobi memang harus selektif memilih individu yang dapat memengaruhi orang lain, mendominasi, mengarahkan diskusi, dan memiliki minat khusus pada jenis undang-undang tertentu. Suksesnya lobi amat bergantung dengan informasi yang disampaikan pelobi kepada individu yang berpengaruh. Maka dari itu informasi dapat dikatakan sebagai sebuah kekuatan. Pelobi paling efektif sering kali adalah orang yang memberikan informasi terbaik (Grunig \& Hunt, 1984).

"Selama ini hubungan baik (dengan pemangku kepentingan) itu terjalin dengan sangat intens. Mengerti dengan baik bahwa UU ini sangat diperlukan oleh konsultan pajak dalam rangka kontribusi dan prestasi mereka dalam membantu kita untuk mengamankan penerimaan pajak," (MM)

Komponen selanjutnya dalam kegiatan lobi adalah menyiapkan pembicara dan saksi ahli. MM sebagai legislator sekaligus inisiator RUU Konsultan Pajak memang memposisikan dirinya sebagai pembicara utama. MM yang memiliki background pendidikan Diploma III Perpajakan, Sarjana Ekonomi, Magister Hukum Bisnis serta pengalaman kerja sebagai mantan Pegawai Negeri Sipil (PNS) di Direktorat Jenderal Pajak (DPR RI, 2020a) memiliki pengetahuan yang mendalam tentang konsultan pajak. Sebelum pelobi fokus dalam debat, mereka juga harus mengumpulkan informasi dari para saksi ahli yang mampu memberikan data yang mendukung pandangan mereka. Begitu pentingnya peran saksi ahli sehingga perusahaan public relations memasukkan pelatihan dan persiapan juru bicara sebagai bagian dari layanan mereka. Pelatihan juru 
bicara melibatkan persiapan laporan latar belakang yang lengkap, mengadakan briefing, dan bahkan melatih pembicara menggunakan rekaman video dan anggota staf yang memainkan peran sebagai penanya antagonis (Grunig \& Hunt, 1984).

Pengalaman MM sebagai anggota DPR tentu membuatnya familiar dengan suasana debat. Debat dapat dijumpai dalam rapat usulan, harmonisasi hingga pembahasan. Kecakapan untuk mempertahankan argumen saat debat tentu dibutuhkan. Di saat inilah kepentingan dari berbagai pihak dipertarungkan. Akan sangat baik jika pelobi mendapatkan dukungan dari akar rumput. Membuat petisi bisa menjadi jalan pelobi untuk mendapatkan dukungan publik yang lebih luas. Selain itu, pelobi juga dapat mencari dan mengembangkan dukungan vokal dari lembaga-lembaga pemerintah yang memiliki kepedulian bersama dalam undang-undang tertentu, dan bersedia membawa kekuatan mereka sendiri yang cukup besar untuk mendukung debat publik (Grunig \& Hunt, 1984).

Dalam proses negosiasi, hal pertama yang dilakukan MM beserta mitra koalisi adalah mengonstruksi isu melalui argumen, narasi, justifikasi, hingga pembuatan kasus yang tersusun rapi dan konsisten. Hal ini mereka lakukan agar publik dapat merespon secara positif RUU Konsultan Pajak. Sebagai contoh, mereka berkali-kali menyebut di banyak liputan media massa bahwa RUU Konsultan Pajak dapat meningkatkan penerimaan pajak negara dan memberikan edukasi serta informasi kepada para wajib pajak. Selain itu, mereka juga memberikan contoh kasus yakni adanya kesenjangan antara Jepang dan Indonesia dalam hal jumlah konsultan pajak. Secara kontinu dan konsisten contoh kasus itu selalu dijabarkan dalam seminar, diskusi publik, ataupun sosialisasi ke media massa. Jika formula framing ini tetap dipertahankan, tidak menutup kemungkinan pemangku kepentingan akan terpengaruh dan posisi tawar juga akan meningkat (Barge, 2009).

Setelah dianalisis, MM yang didukung oleh IKPI memilih model strategi dominan yang mana ia secara stabil dan konsisten menggunakan strategi integratif selama proses negosiasi berlangsung. MM mengklaim dirinya terbuka pada informasi dan masukkan, jujur dengan kepentingannya, menganggap hubungan dengan pihak lain penting, dan menginginkan solusi yang saling menguntungkan.

"Kami secara terbuka mempersilahkan berbagai pihak untuk meberikan masukan terkait RUU Konsultan Pajak," (MS)

Paalvola (2014) mengatakan bahwa strategi integratif mengandalkan pendekatan kooperatif agar kedua pihak secara bersama-sama mendapatkan hasil yang maksimal. Tidak jarang, negosiator yang menggunakan strategi ini mengorbankan kebutuhan pribadi mereka demi tercapainya tujuan kolektif. Hal ini mereka lakukan untuk menjaga hubungan baik di masa depan (Pon, 2014). Berbagai literatur yang membahas strategi integratif (Fells, 2016; Kong, 2015; Miles \& Clenney, 2012) juga menjelaskan bahwa negosiator integratif menempatkan penekanan kuat pada tingkat kepercayaan dan komitmen yang tinggi untuk mengintegrasikan ideide mereka dengan rekan-rekan mereka untuk mendapatkan hasil yang bermakna. Pola pikir negosiator integratif yang selalu mencari klarifikasi dari berbagai pihak membuat mereka sering berhasil mencapai tujuan kolektif. Hal ini tentu membawa manfaat bagi semua pihak yang terlibat (Abigail, Eden, \& Ideris, 2018; Goering, 1997; Harinck \& De Dreu, 2004; Walto \& Mickersie, 1965).

Tahap terakhir kegiatan komunikasi dalam proses negosiasi adalah mengelola hubungan baik dengan konstituen. Pada kasus RUU Konsultan Pajak, konstituen utama MM adalah IKPI. MM mengatakan bahwa ia menjalin komunikasi yang intens dengan IKPI dan bertindak sebagai agen yang mewakili posisi dan kepentingan IKPI di DPR. Hubungan antar agen dan konstituen penting untuk dikelola dengan baik, karena berimplikasi pada dukungan 
yang diberikan konstituen pada rapatrapat di DPR. IKPI sendiri dapat mewakili suara publik dan berdampak memengaruhi keputusan pemangku kepentingan.

"Ketua Umum IKPI secara langsung memimpin seluruh proses pembahasan RUU Konsultan Pajak di DPR," (MS)

"Selama menginisiasi UU Konsultan Pajak ini, saya banyak berhubungan dengan ikatan konsultan pajak. Sebuah ikatan, organisasi profesi yang memayungi, dan saya anggap yang paling besar di bidang konsultan pajak," (MM)

Dalam melakukan lobi dan negosiasi, MM menemukan adanya gangguan. Gangguan tersebut datang dari akademisi dan pakar perpajakan yang kontra dengan RUU Konsultan Pajak. Para pihak yang kontra menyebut bahwa RUU tersebut hanya akan menguntungkan satu organisasi tertentu dan bukan bagian dari reformasi perpajakan. Managing Partner Danny Darussalam Tax Center (DDTC) Darussalam mengatakan bahwa RUU Konsultan Pajak masih belum memperhatikan kepentingan semua stakeholder. RUU Konsultan Pajak juga sebaiknya diharmonisasikan dengan Undang-Undang Ketentuan Umum dan Tata Cara Perpajakan atau KUP yang saat ini juga sedang dibahas di DPR. Sementara, Guru Besar Ilmu Kebijakan Pajak Universitas Indonesia, Haula Rosdiana yang mewakili kalangan akademisi, menjelaskan bahwa RUU Konsultan Pajak dapat mendegradasi peran pemerintah. Penyebutan nama organisasi tertentu dalam RUU Konsultan Pajak juga akan menimbulkan distrust effect, policy cost, dan compliance cost. Selain itu terjadi override RUU Konsultan Pajak atas UU KUP. Rosdiana juga secara khusus meminta DPR mengakomodir kepentingan dunia pendidikan terutama yang terkait dengan perpajakan dalam RUU Konsultan Pajak (Suwiknyo, 2018). Terlepas dari berbagai polemik yang ada, RUU Konsultan Pajak faktanya lolos dalam daftar Prolegnas prioritas tahun 2018 setelah melewati berbagai tahapan yang dibuat Baleg DPR dan menyingkirkan puluhan RUU lainnya.
Tentunya ada kontribusi MM dan mitra koalisi yang melakukan praktik lobi dan negosiasi di DPR.

\section{E. KESIMPULAN}

Berdasarkan hasil penelitian dan pembahasan, dapat ditarik kesimpulan dalam penelitian ini. Pertama, MM sebagai komunikator politik menempatkan posisinya sebagai politisi partisan yang melakukan lobi dan negosiasi berdasarkan kepentingan partainya dan IKPI sebagai organisai yang diklaim akan diuntungkan jika RUU Konsultan Pajak disahkan pemerintah. Kedua, lima area dasar kegiatan lobi yang dijalankan MM diantaranya (1) menjalin koalisi dengan organisasi berpengaruh yaitu IKPI yang memang memiliki kepentingan yang sama, (2) melakukan riset pendahuluan dan persiapan laporan untuk dibahas saat rapat pembahasan, (3) menjalin komunikasi dengan individu berpengaruh dalam Baleg DPR dan anggota fraksi dari partai lain, (4) menetapkan MM sebagai pembicara sekaligus saksi ahli dan terakhir (5) mempersiapkan diri dalam debat di DPR.

Ketiga, dalam proses negosiasi, MM beserta mitra koalisi mengonstruksi narasi yang disebarluaskan kepada publik dan pemangku kepentingan yaitu RUU Konsultan Pajak dapat meningkatkan penerimaan pajak negara dan memberikan edukasi serta informasi kepada para wajib pajak.

Kemudian, strategi negosiasi yang dipilih MM adalah strategi integratif yang terbuka terhadap masukan, jujur dengan kepentingan, dan menghasilkan solusi yang saling menguntungkan. Selain itu, MM juga secara aktif mengelola hubunganya dengan IKPI yang dalam konsep negosiasi disebut sebagai konstituen. Keempat, meskipun menemui gangguan saat proses lobi dan negosiasi di DPR, MM berhasil meyakinkan para pemangku kepentingan untuk merestui RUU Konsultan Pajak masuk dalam daftar Prolegnas Prioritas tahun 2018. 


\section{REFERENSI}

Abigail, D., Eden, D., \& Ideris, A. (2018). A Review of Distributive and Integrative Strategies in the Negotiation Process. Malaysian Journal of Social Sciences and Humanities (MJSSH), 3(5), 68-74. Retrieved from https://msocialsciences.com/index.php/mjssh/ article/view/152

Alexander, N., Howieson, J., \& Fox, K. (2015). Negotiation: Strategy, Styles, Skills. Chatswood, New South Wales: LexisNexis Butterworths.

Arroyo, E., Connor, J., Gardner, R., Lacovar, P., \& McCarthy, M. (2002). The ethics of lobbying: Organized interests, political power, and the common good. Washington, DC: Georgetown University Press.

Badan Legislasi DPR RI. (2018). RUU Konsultan Pajak Untuk Tingkatkan Penerimaan Pajak Negara. Retrieved January 18, 2020, from http://www.dpr.go.id/berita/detail/ $\mathrm{id} / 21059 / \mathrm{t} / \mathrm{RUU}+$ Konsultan+Pajak+Untuk+Tingkatkan+Penerimaan+Pajak+Negara

Barge, K. (2009). Negotiation Theory. In S. W. Littlejohn \& K. A. Foss (Eds.), Encyclopedia of Communication Theory. Thousand Oakes: SAGE Publications.

Barus, K. (2018). Urgensi RUU Konsultan Pajak dalam Reformasi Perpajakan. Retrieved January 19, 2020, from https://www.industry.co.id/read/54565/urgensi-ruu-konsultanpajak-dalam-reformasi-perpajakan

Berg, K. (2009). Finding Connections between Lobbying, Public Relations and Advocacy. Public Relations Journal, 3(3), 1-19.

Carey, J. W. (1965). THE COMMUNICATIONS REVOLUTION AND THE PROFESSIONAL COMMUNICATOR. The Sociological Review, 13(S1), 23-38. https://doi.org/10.1111/ j.1467-954X.1965.tb03107.x

Castleberry, A., \& Nolen, A. (2018). Thematic analysis of qualitative research data: Is it as easy as it sounds? Currents in Pharmacy Teaching and Learning, 10(6), 807-815. https://doi. org/https://doi.org/10.1016/j.cptl.2018.03.019

Čulo, K., \& Skendrović, V. (2012). COMMUNICATION IN THE PROCESS OF NEGOTIATION. Informatol, 45(4), 323-327.

Dondero, R., \& Lunch, W. (2005). Interest groups. In R. Clucas, M. Henkels, \& B. Steel (Eds.), Oregon politics and government: Progressives versus conservative populists. Lincoln: University of Nebraska.

Doob, L. W. (1948). Public opinion and propaganda. Public opinion and propaganda. Oxford, England: Henry Holt.

DPR RI. (2004). UU No. 10 Tahun 2004 tentang Pembentukan Peraturan Perundang-undangan.

DPR RI. (2016). Program Legislasi Nasional. Retrieved January 20, 2020, from http://www. dpr.go.id/prolegnas/index/id/184

DPR RI. (2020a). Daftar Anggota DPR RI: H. MUKHAMAD MISBAKHUN, S.E., M.H. Retrieved January 22, 2020, from http://www.dpr.go.id/anggota/detail/id/531

DPR RI. (2020b). Draf RUU tentang Konsultan Pajak. Retrieved from http://www.dpr.go.id/ doksileg/proses2/RJ2-20181119-115426-3532.pdf

DPR RI. (2020c). Program Legislasi Nasional 2020-2024. Retrieved January 20, 2020, from http://www.dpr.go.id/uu/prolegnas-long-list

Edgett, R. (2002). Toward an ethical framework for advocacy in public relations. Journal of Public Relations Research, 14(1), 1-26. 
Fauzan, A. (2015). Lobbying and Negotiation. Retrieved January 15, 2020, from http://koransindo.com/page/news/2015-11-12/5/79/Lobbying_and_Negotiation

Fells, R. (2016). Effective negotiation: From research to results. Cambridge University Press.

Goering, E. (1997). Integrative verses distribution in contract negotiation. An interaction analysis of Strategy use. Journal of Business Communication, 34, 383-400.

Grunig, J., \& Hunt, T. (1984). Managing Public Relations. New York: CBS College Publishing.

Hammarberg, K., Kirkman, M., \& de Lacey, S. (2016). Qualitative research methods: when to use them and how to judge them. Human Reproduction, 31(3), 498-501. https://doi. org/10.1093/humrep/dev334

Harinck, F., \& De Dreu, C. K. W. (2004). Negotiating interests or values and reaching integrative Agreements: the importance of time pressure and temporary impasses. European Journal of Social Psychology, 34, 596-611.

Henry, F., Lawrence, E., \& Sides, J. (2010). Self-Segregation or Deliberation? Blog Readership, Participation, and Polarization in American Politics. Perspectives on Politics, 8(1), $141-$ 157.

Hidayat, R. (2018). Ini 27 RUU Prolegnas 2019 Berstatus Pembahasan Tingkat Pertama. Retrieved from https://www.hukumonline.com/berita/baca/lt5be0022943bcc/ini-27ruu-prolegnas-2019-berstatus-pembahasan-tingkat-pertama/

Joos, K. (2011). Lobbying in the new Europe. Boschstr: Wiley-VCH.

Katz, D. (1960). The functional approach to the study of attitudes. Public Opinion Quarterly, 24(2), 163-204. https://doi.org/10.1086/266945

Koeppl, P.(2000). The acceptance, relevance and dominance of lobbying the EU Commission-A first-time survey of the EU Commission's civil servants. Journal of Public Affairs, 1(1), 69-80.

Kong, D. (2015). Narcissists' negative perception of their counterpart's competence and benevolence and their own reduced trust in a negotiation context. Personality and Individual Differences, 74, 196-201.

Milbrath, L. (1960). Lobbying as a communications process. Public Opinion Quarterly, 24(1).

Miles, E., \& Clenney, E. (2012). Extremely difficult negotiator goals: Do they follow the Predictions of Goal-setting theory? Organizational Behavior and Human Decision Processes, 118(2), 108-115.

Mohajan, H. (2018). Qualitative Research Methodology in Social Sciences and Related Subjects. Journal of Economic Development, Environment and People, 7(1), 23-48.

Nimmo, D. (2006). Komunikasi Politik: Komunikator, Pesan dan Media. Bandung: Remaja Rosdakarya.

Ortax.org. (2018). RUU Konsultan Pajak Segera Disahkan? Retrieved January 20, 2020, from https://www.ortax.org/ortax/?mod=video\&page = show\&id=88

Paalvola. (2014). Negotiation strategies and offers.

Pon. (2014). Hard-bargaining tactics and negotiation skills. Retrieved January 22, 2020, from https://www.pon.harvard.edu/daily/batna/10-hardball-tactics-in-negotiation/

Ryandi, D. (2018). Legislator Golkar ini Ngotot Indonesia Wajib Punya RUU Konsultan Pajak. Retrieved January 22, 2020, from https://www.jawapos.com/nasional/ 
politik/03/05/2018/legislator-golkar-ini-ngotot-indonesia-wajib-punya-ruu-konsultanpajak/

Setiawan, A. (2018). Baleg DPR Loloskan RUU Konsultan Pajak, 13 Poin Disepakati. Retrieved January 20, 2020, from https://news.ddtc.co.id/baleg-dpr-loloskan-ruu-konsultanpajak-13-poin-disepakati-13127\#.W0x-mw17hrM.whatsapp

Shahreza, M. (2018). Proses dan Elemen-Elemen Komunikasi Politik. Retrieved January 15, 2020, from https://doi.org/10.31227/osf.io/9zh46

Shell, G. (2006). Bargaining for Advantage: Negotiation Strategies for Reasonable People. Penguin Book.

Shonk, K. (2018). 10 Notable Negotiations of 2018. Retrieved January 15, 2020, from https:// www.pon.harvard.edu/daily/negotiation-skills-daily/notable-negotiations-of-2018/

Sukarelawati, E. (2019). IKPI dorong DPR segera tuntaskan RUU Konsultan Pajak. Retrieved January 20, 2020, from https://www.antaranews.com/berita/1023772/ikpi-dorongdpr-segera-tuntaskan-ruu-konsultan-pajak

Suwiknyo, E. (2018). RUU Konsultan Pajak Menuai Polemik. Retrieved January 18, 2020, from https://finansial.bisnis.com/read/20180911/10/837228/ruu-konsultan-pajak-menuaipolemik

Thompson, J., Ebner, N., \& Giddings, J. (2017). Nonverbal Communication in Negotiation. In C. Honeyman \& A. Schneider (Eds.), The Negotiator's Desk Reference. St Paul: DRI Press. Retrieved from https://ssrn.com/abstract=3136798

Walto, E., \& Mickersie, R. (1965). A behavioral theory of Labor negotiations. An Analysis for a Social interaction system. New York: Mc Graw Hill.

White, J., \& Ypi, L. (2016). The meaning of partisanship. Oxford: Oxford University Press.

Zohar, I. (2015). "The Art of Negotiation" Leadership Skills Required for Negotiation in Time of Crisis. Procedia - Social and Behavioral Sciences, 209, 540-548. https://doi.org/ https://doi.org/10.1016/j.sbspro.2015.11.285

Zorack, J. (1990). The lobbying handbook. Washington, DC: Professional Lobbying and Consulting Center. 